\title{
Temporal and ontogenetic variation in the escape response of Ameiva festiva (Squamata: Teiidae)
}

\author{
Matthew S. Lattanzio ${ }^{1,2}$ \\ ${ }^{1}$ Department of Zoology, University of Oklahoma, Norman, OK 73019, USA. \\ ${ }^{2}$ Current address: Department of Organismal and Environmental Biology, Christopher Newport University, Newport News, \\ VA 23606, USA. E-mail: matthew.lattanzio@cnu.edu.
}

\begin{abstract}
Temporal and ontogenetic variation in the escape response of Ameiva festiva (Squamata, Teiidae). Several factors have been shown to affect lizard escape behavior (flight initiation distance or FID, the distance between predator and prey when the prey initiates escape). Patterns of daily activity, such as foraging or movement behavior, vary with respect to time of day, supporting that escape responses may vary temporally as well. However, there remains scant information regarding the effects of time of day on FID. During peak activity, FID may decrease due to increased cost of giving up resources (e.g., prey or potential mates). An alternative hypothesis is that FID may increase because lizard activity in general may serve to alert a predator in advance of its approach. A lizard in this scenario may be favored to flee sooner rather than later. Moreover, juvenile and adult lizards of multiple species may differ in behavioral, ecological, and morphological traits that could influence escape decisions. I tested the effects of time of day (in 30-min intervals) and age (juvenile or adult) on the FID of a tropical whiptail lizard, Ameiva festiva in Costa Rica. I found that A. festiva escape responses varied with time of day such that in general, their FID decreased throughout the day. In addition, I observed a peak in FID from mid to late-morning that matches published estimates of peak activity times for A. festiva. Overall, juvenile $A$. festiva initiated an escape response sooner than adults, which may be related to differences in perceived risk associated with differences in size and predator experience between the two age groups. I conclude that escape responses may be contingent on both the activity level of the animal at the time of approach and its age.
\end{abstract}

Keywords: activity pattern, age, flight initiation distance, lizard, optimal escape theory, time of day. 


\begin{abstract}
Resumo
Variação temporal e ontogenética na resposta de fuga de Ameiva festiva (Squamata, Teiidae). Diversos fatores podem influenciar o comportamento de fuga dos lagartos (distância de início da fuga ou FID, a distância entre o predador e a presa quando esta inicia a fuga). Os padrões diários de atividade, como os comportamentos de forrageio ou de movimentação, variam em função da hora do dia, sustentando a ideia de que as respostas de fuga podem variar também temporalmente. Contudo, permenecem escassas as informações relacionadas aos efeitos da hora do dia sobre a FID. Durante o pico de atividade, a FID pode diminuir devido ao aumento do custo de desistir de recursos (e.g., presas ou parceiros potenciais). Uma hipótese alternative é a de que a FID pode aumentar porque a atividade do lagarto em geral pode servir para alertar um predador antes de sua aproximação. Esse cenário pode favorecer a fuga precoce de um lagarto, em vez de tardia. Além disso, lagartos juvenis e adultos de diversas espécies podem diferir em características de comportamento, ecológicas e morfológicas que poderiam influenciar as decisões de fuga. Testei os efeitos da hora do dia (em intervalos de $30 \mathrm{~min}$ ) e da idade (juvenil ou adulto) sobre a FID de um lagarto teiídeo tropical, Ameiva festiva, na Costa Rica. Descobri que as respostas de fuga de A. festiva variaram com a hora do dia, de modo que, em geral, sua FID diminuiu ao longo do dia. Adicionalmente, observei um pico da FID do meio para o final da manhã que coincide com as estimativas das horas de pico de atividade de A. festiva publicadas na literatura. Em geral, os juvenis de A. festiva iniciaram uma resposta de fuga mais cedo do que os adultos, o que pode estar relacionado com diferenças no risco percebido associado a diferenças no tamanho e na experiência com o predador entre os dois grupos etários. Concluo que as as respostas de fuga podem depender tanto do nível de atividade do animal no momento da aproximação como de sua idade.
\end{abstract}

Palavras-chave: distância de início da fuga, hora do dia, idade, lagarto, padrão de atividade, teoria da fuga ótima.

\section{Introduction}

Optimal escape theory has been extensively used to generate predictions regarding the response of an organism to an approaching predator by focusing on the potential trade-offs between the risk of remaining and the costs of escape (Ydenberg and Dill 1986, Martín and López 1995, Cooper Jr. and Frederick 2007, Lattanzio 2009, Cooper Jr. and Avalos 2010). In most studies, the distance between predator and prey when the prey initiates escape (deemed flight initiation distance [FID]) is modeled as the escape response. This distance appears to be an accurate measure of the tradeoff between the risk of remaining versus the cost of fleeing for several taxa (Cooper Jr. and Frederick 2007). For lizards in particular, multiple factors may affect this tradeoff and thus their FID, including approach speed of the predator (Amo et al. 2003, Cooper Jr. 2003), attack persistence (Paulissen 1995,
Martín and López 2003), directness of predatory approach (Cooper Jr. 2003), distance from prey to refuge (Bulova 1994), and presence of food (Cooper Jr. and Peréz-Mellado 2004).

In addition, because lizard activity patterns vary throughout the day (e.g., Winne and Keck 2004, Lattanzio and LaDuke 2012), the time of day of a predator's approach to an individual lizard may also affect its escape response. For example, in lizards of the genus Ameiva (Teiidae), foraging and mating activity typically peaks late-morning and diminishes thereafter (Vitt and Colli 1994, Blazquez 1996). At times of greater activity, these lizards may allow closer approaches because the cost of giving up resources (i.e., potential food or mates) are likely higher during these periods. Indeed, Balearic lizards (Podarcis lilfordi) allow closer predator approach when food is present (i.e., provided to them, see Cooper Jr. and Peréz-Mellado 2004). An alternative hypothesis is that active lizards 
may flee sooner when foraging because foraging activity alone may alert a predator to their presence (e.g., Martín and López 2001). In this scenario, the risk of predation should be elevated prior to predator detection, possibly due to the noise generated by normal foraging or mate searching behavior, and thus escape should be initiated soon after a predator begins its approach. Alternatively, FID may also be affected by other factors that vary throughout the day, such as temperature (Cooper Jr. 2000, 2003). Lizard activity and life histories are strongly tied to temperature (Adolph and Porter 1993), and air and substrate temperature in particular can affect their locomotor capacity (Crowley 1985) and movement rates (Grant and Dunham 1988). These temperatures should also influence the costs associated with fleeing a predator at different times of day, thereby affecting FID (e.g., Cooper Jr. 2000). Both time of day (relative to lizard activity) and temperature are thus important considerations for studies of escape behavior in the wild.

The effect of ontogeny on lizard escape behavior has received more attention than time of day but results generally differ among taxa with respect to which age group (juvenile or adult) allows a closer approach by a predator (e.g., Martín and López 1995, Whiting et al. 2003). In many lizard species, juveniles and adults differ in several traits including behavior (Castilla and Bauwens 1991, Blazquez 1996), morphology (Vitt and Colli 1994), performance capacity (Garland 1985, Irschick 2000), and ecology, particularly regarding diet or microhabitat use (Stamps 1983, Durtsche 2000, Lattanzio and LaDuke 2012). Juvenile lizards may also exhibit a reduced locomotor capacity compared to adults (e.g., sprint speed, Garland 1985). Collectively, these ontogenetic dissimilarities suggest that age may also have an effect on how the risk-cost tradeoff associated with an approaching predator manifests. Thus, it is likely that the realized escape response (FID) of juvenile and adult lizards may also differ. Specifically, juveniles may be expected to exhibit greater FID than adults given these considerations (but see Whiting et al. 2003).

In this study I test for an effect of time of day and age (juvenile or adult) on the escape response (FID) of whiptail lizards, Ameiva festiva (Squamata, Teiidae). Ameiva festiva is a widelyforaging insectivorous lizard common throughout lowland Costa Rica (Figure 1) (Savage 2002).

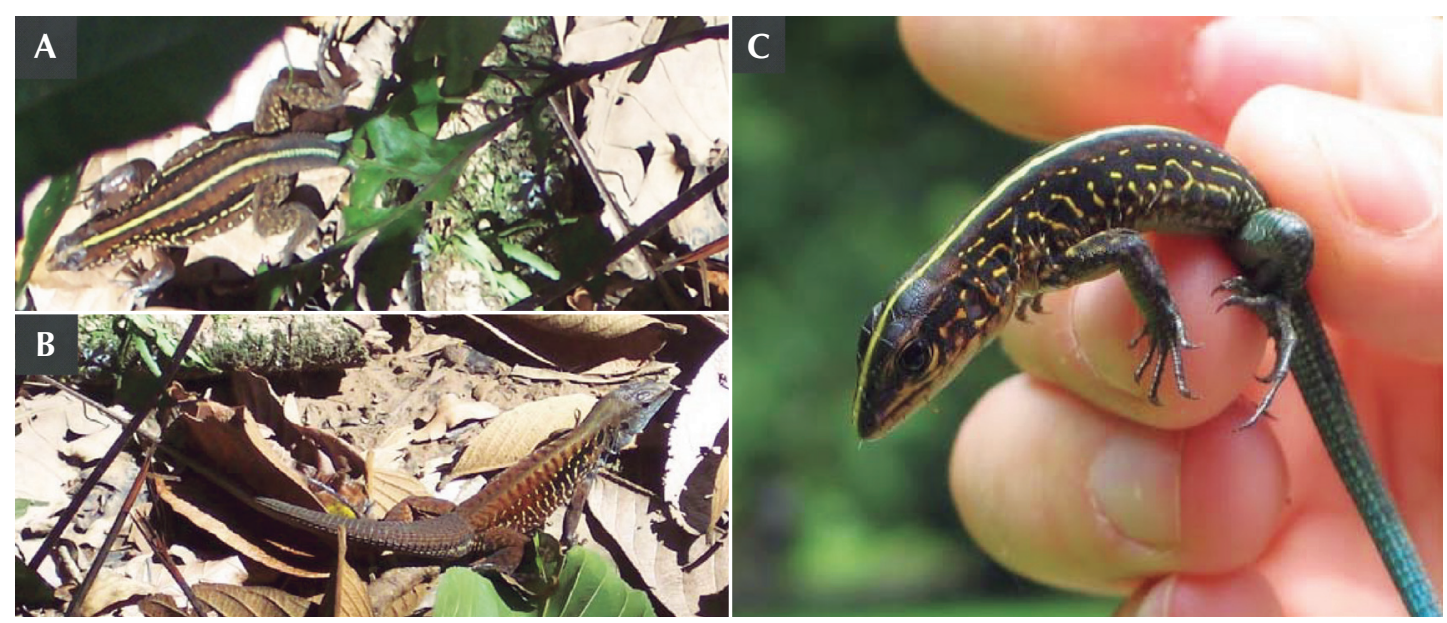

Figure 1. Examples of adult female (A) and male (B), and juvenile (C) Ameiva festiva. Photographs by Matthew S. Lattanzio (A, B) and Vincent R. Farallo (C). 
However, data on the behavior of A. festiva are lacking. To date, much research has focused on their energetics (Morgan 1988), reproduction (Smith 1968a, b), diet (Whitfield and Donnelly 2006), and habitat use (Hillman 1969). In addition, Vitt and Zani (1996) describe daily activity of A. festiva throughout the day as exhibiting a peak in activity in the late-morning hours. Other aspects of A. festiva behavior, including the escape response, have not yet been addressed.

Finally, because lizard behavior and life history variation is closely tied to temperature (Adolph and Porter 1993), I also evaluated the relationships between air and substrate (initial observation point) temperature and lizard FID. A significant correlation between temperature and lizard FID would suggest that escape responses are associated with variation in environmental conditions. That is, lizards may flee sooner when temperatures are lower to compensate for a potential decrement in locomotor performance capacity (e.g., Crowley 1985, Angilletta et al. 2002). Because peak movement and foraging activity for A. festiva occurs during the latemorning hours (e.g., Hillman 1969, Vitt and Zani 1996), and because these behaviors will likely alert predators of their presence (e.g., Martín and López 2001, Lattanzio pers. observ.), I predict that lizards will flee sooner (greater FID) in the mid- late-morning hours, and that FID should decrease thereafter for the remainder of the day.

\section{Materials and Methods}

I observed the escape responses of juvenile and adult A. festiva for five sunny days in July 2007 at El Zota Biological Field Station in northeast Costa Rica $\left(10^{\circ} 57.6^{\prime} \mathrm{N}, 83^{\circ} 75.9^{\prime} \mathrm{W}\right.$, Pruetz and LaDuke 2001). El Zota encompasses approximately 1,000 ha of mixed primary and secondary forest, and experiences mild seasonality with rainfall peaks in early summer (April-June) and late fall (November-December) (Lattanzio and LaDuke 2012). A. festiva in this region frequent habitat edges along dirt roads, trails, and fields (Lattanzio pers. observ.).

Although movement and foraging activity of A. festiva peaks from mid to late-morning, lizards may be observed active throughout the day (Vitt and Zani 1996). I simulated an approaching predator in order to elicit an escape response from each lizard, using the following procedure. I searched for A. festiva lizards at the study site from 07:30-17:30 h on each survey day by walking slowly through the habitat until I sighted a lizard. Upon encountering a lizard, I stopped briefly and then began my approach by walking in a direct, straight path towards the animal at a practiced, constant pace $(\sim 80 \mathrm{~m} / \mathrm{min})$, similar to previous studies (e.g., Cooper Jr. 2003, Cooper Jr. and Avalos 2010). After the lizard fled, I measured its FID to the nearest $0.1 \mathrm{~m}$. I also measured my detection distance (starting distance between myself and the lizard prior to my approach) to the nearest $0.1 \mathrm{~m}$. Adult $A$. festiva are sexually dimorphic in size and pattern (Savage 2002; see also Figure 1) and sex can be determined by visual inspection. Moreover, juvenile A. festiva are distinguishable from adult lizards given their bright, blue-colored tail (see Figure 1). I identified the age (juvenile or adult) and sex (adults only, male or visibly non-gravid female) of each lizard based on these considerations, and only approached those lizards that could be clearly assigned to one of those three categories. I recorded the time of day of each FID measurement, to the nearest 30 minutes (e.g., 08:00 h, 08:30 h etc.).

In addition, some support exists for environmental temperatures affecting the escape response (Blamires 1999, Cooper Jr. 2000, 2003). Air temperature was recorded to the nearest $0.5^{\circ} \mathrm{C}$ at 15 -minute intervals using an outdoor tube thermometer affixed to a wooden post at a location approximating the center of the study site by another researcher. Temperatures were recorded at a height of $\sim 1.5 \mathrm{~m}$ in an open field (i.e., zero canopy cover), and I obtained the air temperature that corresponded to each time 
that I observed the escape response of a lizard from this dataset. A. festiva are wide-ranging actively-foraging lizards that exploit edge and open-canopy microhabitats which likely expose these lizards to a similar air temperature to the air temperature data I recorded. However, my estimates of air temperature represent only a subset of potential temperatures available to heliothermic lizards like A. festiva to utilize for thermoregulation. I therefore treat these data as an approximation of maximum possible daily conditions, and not a precise measurement of local conditions at A. festiva initial observation points. I also recorded substrate temperature (nearest $0.5^{\circ} \mathrm{C}$ ) at the initial observation point of each lizard with the aid of an infrared thermometer (Extech Instruments Corp., Nashua, $\mathrm{NH}$, USA). It should be noted that although body temperature may also affect the escape response of lizards (e.g., Smith 1997), the non-invasive nature of my study precluded estimation of individual lizard body temperatures. In addition, the covariation between environmental temperatures and lizard body temperature is often inconsistent, particularly if the animal thermoregulates (Huey and Slatkin 1976). I therefore do not use air and substrate temperature data as a proxy for body temperature, and instead treat the relationships between those environmental temperatures and A. festiva FID directly. Each day, a different area was surveyed within the study site to ensure that no lizard was observed more than once. The distance between adjacent survey areas was always $\geq 100 \mathrm{~m}$. I wore clothing that was similar in color, make, and wear during all surveys.

I observed the escape responses of 33 juvenile, 11 adult male, and 14 adult female $A$. festiva. I conducted all statistical analyses in the program R 3.0.2 (R Development Core Team 2012). A preliminary analysis indicated that male and female FID overlapped $(t=-0.539$, df $=23, P=0.595)$, and thus I pooled adults $(\mathrm{n}=$ 25 ) for subsequent analyses. Separate correlation tests were used to evaluate the relationship between air and substrate temperature and FID. I used an analysis of covariance (ANCOVA) to determine the effect of lizard age on FID, with time of day as the covariate. I did not include microhabitat as a factor because adult and juvenile lizards used the same microhabitat types (bare ground and leaf litter). Preliminary analysis indicated no relationship between detection (starting) distance and FID $(t=1.17, r=0.154$, df $=56, P=0.249$ ), and thus I also excluded this term from the ANCOVA. For the ANCOVA, I first standardized time of day to a mean of zero and unit standard deviation. I then included standardized time of day in the model as both a linear and a quadratic (squared values) term. The quadratic term is critical for determining whether there is a non-linear effect of time on FID (i.e., is there one or multiple peaks in FID during the day?). A positive slope of FID on the quadratic term would suggest two FID peaks (i.e., high FID at two different times of day) and a negative slope would indicate one peak in FID during the day. No temporal autocorrelation was detected as there is no relationship between model residuals and time of day $(r=-0.007, t=-0.05$, df $=56, P=$ 0.961). I use the Akaike Information Criterion (AICc, corrected for small sample size; Burnham and Anderson 2002) to interpret model fit and I report unstandardized effect sizes (i.e., regression coefficient, $\beta$ ) as $\beta \pm$ standard error (SE) for both the linear and nonlinear time of day term in the ANCOVA. Finally, to visualize the shape of the non-linear relationship between time of day and FID, I fit a cubic spline to the raw data using the 'gam' function in the R package MGCV (Wood 2006).

\section{Results}

Juvenile A. festiva were observed on warmer substrates than adults $\left(F_{1,54}=7.17, R^{2}=0.21, P\right.$ $=0.01$ ). I detected no correlation between either air or substrate temperature and A. festiva FID (air temperature, $t=1.66, r=0.216$, df $=56, P=$ 0.104; substrate temperature, $t=1.6, r=0.209$, $\mathrm{df}=56, P=0.116$ ). 
Given those findings, I did not include temperature data in my ANCOVA. Preliminary analyses indicated that a full model containing both linear and non-linear effects of time of day had greater support than a model containing a linear term alone (AICc full model $=88.608$, AICc linear term only $=95.34, \Delta \mathrm{AICc}=6.732$ ). I therefore present results from the full model. Juvenile lizards had a greater FID than adult lizards $\left(F_{1.52}=6.49, P=0.014\right.$; Figure 2). I detected both a linear and non-linear (quadratic) effect of time of day on FID (linear effect, $\beta=$ $-0.347 \pm 0.09, F_{1.54}=26.77, P<0.001$; nonlinear effect, $\beta=-0.172 \pm 0.11, F_{1,54}=8.97, P=$ 0.004). The FID of A. festiva peaked from about $1000-1130 \mathrm{~h}$, and decreased thereafter for the remainder of the day (Figure 3). Age did not interact with either the linear or non-linear time of day term included in this model (age $\times$ linear effect interaction, $F_{1,52}=0.003, P=0.958$; age $\times$ non-linear effect interaction, $F_{1,52}=0.61, P=$ 0.437).

\section{Discussion}

Adult and juvenile A. festiva were observed in similar microhabitats, which is consistent with published data for this species in other regions (Hillman 1969, Vitt and Zani 1996) However, my findings provide evidence that juvenile lizards may prefer warmer microhabitats than adults. Despite this difference, temperature had no effect on lizard escape responses, which varied only with respect to lizard age and time of day.

One of the predictions of optimal escape theory is that flight initiation distance may increase with perceived risk of predation: greater risk should result in greater FID (Ydenberg and Dill 1986). My findings suggest that FID peaked between mid and late-morning and then decreased for the remainder of the day for all lizards. Interestingly, this peak in FID aligns with peak activity time estimates for A. festiva in other regions (Vitt and Zani 1996). This outcome supports my prediction that lizards at peak

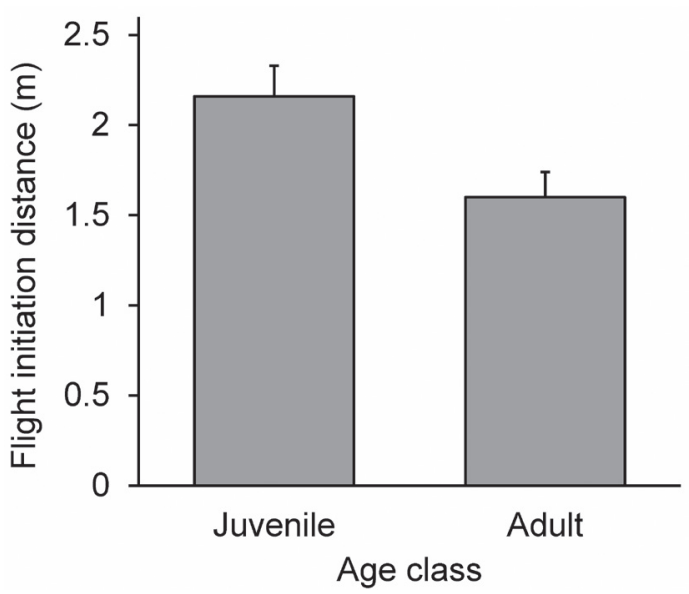

Figure 2. Juvenile $(N=33)$ Ameiva festiva exhibit a greater flight initiation distance (FID) than adult $(N=25)$ lizards. Bars are mean +1.0 standard error (SE).

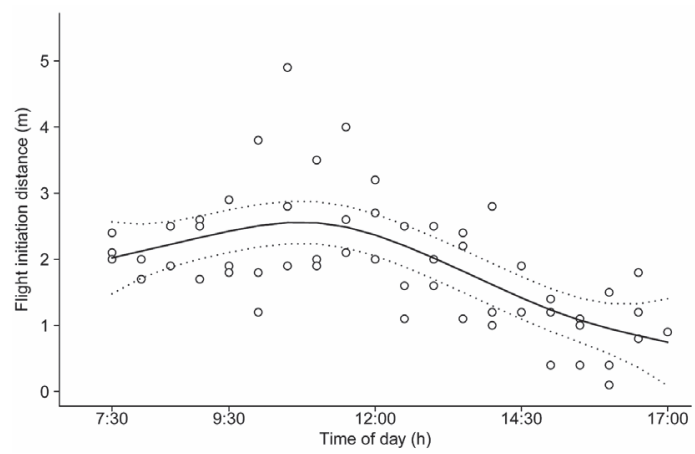

Figure 3. Relationship between flight initiation distance (FID) and time of day for all Ameiva festiva observed in this study $(N=58)$. A cubic spline (solid black line) with 95\% confidence intervals (dotted grey lines) is provided to illustrate the relationship between FID and time of day (see Results).

foraging or mate-searching activity times should flee sooner (greater FID) than at other times of day when the lizards may be less active (e.g., basking). In a controlled-laboratory setting, the presence of food appears to cause lizards to 
decrease, not increase, FID (e.g., Cooper Jr. and Peréz-Mellado 2004). One explanation for a discrepancy between lab and field data centers on the ecology of my study species and other actively-foraging lizards. Although A. festiva foraging behavior may range over a few hours each day (Hillman 1969), most of this time is spent actively moving and digging through leaf litter to search for prey (Savage 2002). As a result, food is likely only present for brief periods during the entire foraging period for a given day (i.e., immediately prior to and during feeding), and food was directly provided to the lizard in Cooper Jr. and Peréz-Mellado (2004), which essentially eliminates any risk of predation associated with foraging. Movement by $A$. festiva in leaf litter (foraging or otherwise) is loud and such behavior may elevate their risk of predation (e.g., Martín and López 2001), either by alerting a predator of their presence in advance or by interfering with their ability to detect the predator as it approaches. Jointly, these considerations support the prediction that, during periods of peak activity, A. festiva should initiate an escape response soon after detecting an approaching predator. More broadly, this prediction is analogous to recent models of escape response strategies by cryptic species (Broom and Ruxton 2005). In lizards, cryptic species typically use a sit-and-wait foraging tactic and their daily activity involves infrequent movement. Thus, for a cryptic species, a lower FID may be favored to avoid alerting a predator of its presence prior to the initiation of an attack (Broom and Ruxton 2005). Similarly, in the late afternoon and early morning hours when $A$. festiva are less-active (Vitt and Zani 1996, Lattanzio, unpubl. data), both juveniles and adults allowed a closer approach (lower FID).

To a broader extent, temporal variation in FID suggests that individual A. festiva may be evaluating the risks and costs associated with an approaching predator differently throughout the day. Appreciation for a temporal effect on FID is scant even though several studies incorporate escape response data collected throughout the day (Blamires 1999, Cooper Jr. et al. 2006, Cooper Jr. 2007). To my knowledge, only one other study addressed the effect of time of day on lizard escape responses (Blamires 1999). In that paper, both time and air temperature were important for the escape response of the agamid Lophognathus temporalis: lizards generally fled sooner in warmer air temperatures and later in the afternoon hours, although the author argues that the latter result may be associated with temperature as well (see Blamires 1999). In this study I used a finer grain temporal scale that enabled modeling both a linear and non-linear effect of time on the escape response of $A$. festiva.

Interestingly, I was unable to detect an effect of air or substrate temperature on FID. This finding suggests that the observed variation in escape behavior of A. festiva may be associated with other factors. If the costs of remaining versus risks of alerting the approaching predator of the presence of the prey are linear, the escape response (FID) can be modeled as a simple distance function (Cooper Jr. and Frederick 2007). However, behavioral trade-offs between activity and predator vigilance occur throughout the day and contribute to variation in daily activity patterns in lizards (e.g., Downes 2001). Consequently, the energy available for escape behavior at any point in time during the day should also vary similarly (and may mirror activity patterns, see Results). In other studies, short, fixed time intervals for observing lizard escape responses are common (Cooper Jr. 2003, Diego-Rasilla 2003). And, in some cases, the exact time frame for behavioral observations is not reported (Cooper Jr. and Peréz-Mellado 2004, Cooper Jr. 2005, 2008). My results however support that temporal variation in escape responses warrants consideration, especially given the potential for escape responses to exhibit a non-linear relationship with time of day (see Figure 3 ). It remains unknown whether other taxa exhibit similar temporal variation in FID [although Fig. 1 of Blamires (1999) suggests temporal variation 
in FID by L. temporalis], and therefore this consideration may represent a potentially fruitful avenue for future work. In particular, for species in which a relationship is detected between environmental temperatures and FID (e.g., Cooper Jr. 2000, 2003), it would be important to include temperature as an additional covariate in the statistical model to disentangle the effects of temperature from other factors related to time of day on escape performance.

My findings also demonstrate that adult $A$. festiva allowed closer approaches than juveniles. It may be that juvenile lizards perceive a greater risk of predation under the same experimental conditions. Differences in the escape responses of juvenile and adult lizards should be expected because age differences are also associated with variation in other traits, including microhabitat use (Stamps 1983, Lattanzio and LaDuke 2012), thermal biology (Castilla and Bauwens 1991), and performance capacity (Irschick 2000). For example, juvenile and adult A. festiva differ in body size, which may affect perception of risk and thus their escape response (López et al. 2005). Older, adult lizards should also have more experience with approaching predators and such experience may influence patterns of FID (Ydenberg and Dill 1986). Given these considerations, juvenile A. festiva may be expected to behave less-boldly than adult lizards under similar predator approach conditions and therefore initiate escape first.

Juvenile A. festiva also exhibit a brightlycolored blue tail that fades at maturity that may serve as a conspicuous signal to attract the attention of predators to their tail, rather than their body (Hawlena et al. 2006). An alternative hypothesis is therefore that juveniles fled earlier than adult lizards in my study because of this trait difference, making it somewhat difficult to pinpoint age as the main effect driving differences in FID in my study. Other juvenile traits typically associated with blue tails (and thus incorporated into this hypothesis) are greater activity levels, tail-distraction displays (e.g., wagging), and striped bodies (Hawlena et al. 2006). However, during my study, I observed juvenile and adult A. festiva active at similar times of day and in similar microhabitats (Lattanzio, unpubl. data). Much of the activity period of teiid lizards like A. festiva of all ages is spent foraging or searching for mating opportunities (e.g., Bennett and Gleeson 1979), behaviors that would likely attract the attention of predators irrespective of differences in tail color. I also did not observe any tail-wagging behavior by either age group, and in A. festiva, adult lizards often retain their striped dorsal pattern (see Figure 1). For juvenile A. festiva, it may not be just age or tail coloration but perhaps a combination of both conspicuousness (in tail coloration) and lack of experience with predator attacks that drive their greater FID. More work is needed however to evaluate whether repeated attacks affect FID in juvenile lizards (i.e., does experience reduce FID, or do blue tails drive the escape response?).

Our understanding of the factors that affect escape decisions has grown much over the past few decades and my results add new insight regarding the relationship between escape behavior and time of day. The relationship I detected between FID and age in my study is clearly not limited to A. festiva and may be associated with any number of age-related factors including reproductive state (Brown and Shine 2004), size (Martín and López 1995), and color pattern (Hawlena et al. 2006), to name a few. Additionally, support for both a linear and non-linear relationship between time of day and FID in my study reveals complexity and variation in the escape response throughout the day. Moreover, an animal's escape response may be at least partly contingent upon its behavior (or degree of activity) prior to being approached by a predator. Further consideration of the nature of these relationships for $A$. festiva and other species will enhance our understanding of the mechanisms contributing to variation in animal escape behavior in the wild. 


\section{Acknowledgments}

This work was conducted with full approval by the University of Oklahoma Animal Care and Use Committee (protocol \#R07-013). Because this research was strictly observational and not conducted within the boundaries of a National Park, no MINAET research permit was required. Funding was provided by a stipend from DANTA Association for Conservation of the Tropics (http://www.danta.info/). The staff at El Zota Biological Field Station provided logistical support. Vincent Farallo, Kortney Jaworski, Anthony Gilbert, and two anonymous reviewers provided helpful comments on earlier permutations of this manuscript.

\section{References}

Adolph, S. C. and W. P. Porter. 1993. Temperature, activity, and lizard life histories. American Naturalist 142: 273295.

Amo, L., P. López, and J. Martín. 2003. Risk level and thermal costs affect the choice of escape strategy and refuge use in the wall lizard, Podarcis muralis. Copeia 2003: 899-905.

Angilletta, M. J., P. H. Niewiarowski, and C. A. Navas. 2002. The evolution of thermal physiology in ectotherms. Journal of Thermal Biology 27: 249-268.

Bennett, A. F. and T. T. Gleeson. 1979. Metabolic expenditure and the cost of foraging in the lizard Cnemidophorus murinus. Copeia 1979: 573-577.

Blamires, S. J. 1999. Factors influencing the escape response of an arboreal agamid lizard of tropical Australia (Lophognathus temporalis) in an urban environment. Canadian Journal of Zoology 77: 1998-2003.

Blazquez, M. C. 1996. Activity and habitat use in a population of Ameiva ameiva in Southeastern Colombia. Biotropica 28: 714-719.

Broom, M. and G. D. Ruxton. 2005. You can run-or you can hide: optimal strategies for cryptic prey against pursuit predators. Behavioral Ecology 16: 534-540.

Brown, G. and R. Shine. 2004. Effects of reproduction on the antipredator tactics of snakes (Tropidonophis mairii, Colubridae). Behavioral Ecology and Sociobiology 56: 257-262.
Bulova, S. J. 1994. Ecological correlates of population and individual variation in antipredator behavior of two species of desert lizards. Copeia 1994: 980-992.

Burnham, K. P. and D. R. Anderson. 2002. Model Selection and Multimodel Inference - a practical informationtheoretic approach. New York. Springer. 488 pp.

Castilla, A. M. and D. Bauwens. 1991. Thermal biology, microhabitat selection, and conservation of the insular lizard Podarcis hispanica atrata. Oecologia 85: 366374.

Cooper Jr., W. E. 2000. Effect of temperature on escape behaviour by an ectothermic vertebrate, the keeled earless lizard (Holbrookia propinqua). Behaviour 137: 1299-1316.

Cooper Jr., W. E. 2003. Risk factors affecting escape behavior by the desert iguana, Dipsosaurus dorsalis: speed and directness of predator approach, degree of cover, direction of turning by a predator, and temperature. Canadian Journal of Zoology 81: 979-984.

Cooper Jr., W. E. 2005. When and how do predator starting distances affect flight initiation distances? Canadian Journal of Zoology 83: 1045-1050.

Cooper Jr., W. E. 2007. Compensatory changes in escape and refuge use following autotomy in the lizard Sceloporus virgatus. Canadian Journal of Zoology 85: 99-107.

Cooper Jr., W. E. 2008. Strong artifactual effect of starting distance on flight initiation distance in the actively foraging lizard Aspidoscelis exsanguis. Herpetologica 64: 200-206.

Cooper Jr., W. E. and A. Avalos. 2010. Escape decisions by the syntopic congeners Sceloporus jarrovii and $S$. virgatus: comparative effects of perch height and of predator approach speed, persistence, and direction of turning. Journal of Herpetology 44: 425-430.

Cooper Jr., W. E. and W. G. Frederick. 2007. Optimal flight initiation distance. Journal of Theoretical Biology 244: 59-67.

Cooper Jr., W. E. and V. Peréz-Mellado. 2004. Tradeoffs between escape behavior and foraging opportunity by the Balearic lizard (Podarcis lilfordi). Herpetologica 60: 321-324.

Cooper Jr., W. E., V. Pérez-Mellado, and D. Hawlena. 2006. Magnitude of food reward affects escape behavior and acceptable risk in Balearic lizards, Podarcis lilfordi. Behavioral Ecology 17: 554-559. 
Crowley, S. R. 1985. Thermal sensitivity of sprint-running in the lizard Sceloporus undulatus: support for a conservative view of thermal physiology. Oecologia 66: 219225.

Diego-Rasilla, F. 2003. Influence of predation pressure on the escape behaviour of Podarcis muralis lizards. Behavioural Processes 63: 1-7.

Downes, S. 2001. Trading heat and food for safety: costs of predator avoidance in a lizard. Ecology 82: 2870-2881.

Durtsche, R. D. 2000. Ontogenetic plasticity of food habits in the Mexican spiny-tailed iguana, Ctenosaura pectinata. Oecologia 124: 185-195.

Garland, T. 1985. Ontogenetic and individual variation in size, shape and speed in the Australian agamid lizard Amphibolurus nuchalis. Journal of Zoology 207: 425-439.

Grant, B. W. and A. E. Dunham. 1988. Thermally imposed time constraints on the activity of the desert lizard Sceloporus merriami. Ecology 69: 167-176.

Hawlena, D., R. Boochnik, Z. Abramsky, and A. Bouskila. 2006. Blue tail and striped body: why do lizards change their infant costume when growing up? Behavioral Ecology 17: 889-896.

Hillman, P. E. 1969. Habitat specificity in three sympatric species of Ameiva (Reptilia: Teiidae). Ecology 50: 476481.

Huey, R. B. and M. Slatkin. 1976. Cost and benefits of lizard thermoregulation. Quarterly Review of Biology 51: 363 384.

Irschick, D. J. 2000. Effects of behaviour and ontogeny on the locomotor performance of a West Indian lizard, Anolis lineatopus. Functional Ecology 14: 438-444.

Lattanzio, M. 2009. Escape tactic plasticity of two sympatric Norops (Beta Anolis) species in Northeast Costa Rica. Amphibia-Reptilia 30: 1-6.

Lattanzio, M. S. and T. C. LaDuke. 2012. Habitat use and activity budgets of emerald basilisks (Basiliscus plumifrons) in northeast Costa Rica. Copeia 2012: 465471.

López, P., D. Hawlena, V. Polo, L. Amo, and J. Martín. 2005. Sources of individual shy-bold variations in antipredator behaviour of male Iberian rock lizards. Animal Behaviour 69: 1-9.

Martín, J. and P. López. 1995. Escape behaviour of juvenile Psammodromus algirus lizards: constraint of or compensation for limitations in body size? Behaviour 132: $181-192$.
Martín, J. and P. López. 2001. Are fleeing "noisy" lizards signalling to predators? Acta Ethologica 3: 95-100.

Martín, J. and P. López. 2003. Changes in the escape responses of the lizard Acanthodactylus erythrurus under persistent predatory attacks. Copeia 2003: 408413 .

Morgan, K. R. 1988. Body temperature, energy metabolism, and stamina in two Neotropical forest lizards (Ameiva, Teiidae). Journal of Herpetology 22: 236-241.

Paulissen, M. A. 1995. Comparative escape behavior of parthenogenetic and gonochoristic Cnemidophorus in southern Texas. Copeia 1995: 223-226.

Pruetz, J. D. and T. C. LaDuke. 2001. New field site: preliminary census of primates at El Zota Biological Field Station, Costa Rica. Neotropical Primates 9: 2223.

R Development Core Team. 2012. R: A language and environment for statistical computing. R Foundation for Statistical Computing, Vienna, Austria.

Savage, J. M. 2002. The Amphibians and Reptiles of Costa Rica: a herpetofauna between two continents, between two seas. Chicago. University of Chicago Press. 954 pp.

Smith, D. G. 1997. Ecological factors influencing the antipredator behaviors of the ground skink, Scincella lateralis. Behavioral Ecology 8: 622-629.

Smith, R. E. 1968a. Experimental evidence for a gonadal-fat body relationship in two teiid lizards (Ameiva festiva, Ameiva quadrilineata). The Biological Bulletin 134: $325-331$.

Smith, R. E. 1968b. Studies on reproduction in Costa Rican Ameiva festiva and Ameiva quadrilineata (Sauria: Teiidae). Copeia 1968: 236-239.

Stamps, J. A. 1983. The relationship between ontogenetic habitat shifts, competition and predator avoidance in a juvenile lizard (Anolis aeneus). Behavioral Ecology and Sociobiology 12: 19-33.

Vitt, L. J. and G. R. Colli. 1994. Geographical ecology of a Neotropical lizard: Ameiva ameiva (Teiidae) in Brazil. Canadian Journal of Zoology 72: 1986-2008.

Vitt, L. J. and P. A. Zani. 1996. Ecology of the lizard Ameiva festiva (Teiidae) in southeastern Nicaragua. Journal of Herpetology 30: 110-117.

Whitfield, S. M. and M. A. Donnelly. 2006. Ontogenetic and seasonal variation in the diets of a Costa Rican leaf-litter herpetofauna. Journal of Tropical Ecology 22: 409-417. 
Whiting, M. J., S. P. Lailvaux, L. T. Reaney, and M. Wymann. 2003. To run or hide? Age-dependent escape behaviour in the common flat lizard (Platysaurus intermedius wilhelmi). Journal of Zoology 260: 123-128.

Winne, C. and M. Keck. 2004. Daily activity patterns of whiptail lizards (Squamata: Teiidae: Aspidoscelis): A proximate response to environmental conditions or an endogenous rhythm? Functional Ecology 18: 314-321.
Wood, S. N. 2006. Generalized Additive Models: an introduction with R. Chapman and Hall/CRC. 410 pp.

Ydenberg, R. C. and L. M. Dill. 1986. The economics of fleeing from predators. Advances in the Study of Behavior 16: 229-249. 